Check for updates

Cite this: RSC Adv., 2017, 7, 43987

Received 21st June 2017

Accepted 7th September 2017

DOI: 10.1039/c7ra06921a

rsc.li/rsc-advances

\section{Enhanced light out-coupling efficiency and reduced efficiency roll-off in phosphorescent OLEDs with a spontaneously distributed embossed structure formed by a spin-coating method}

\author{
Shuqing Yuan, ${ }^{a}$ Yuying Hao, (DD *a Yanqin Miao, (D) ${ }^{\text {b }}$ Qinjun Sun, ${ }^{a}$ Zhanfeng Li, (DD ${ }^{a}$ \\ Yanxia Cui, ${ }^{a}$ Hua Wang ${ }^{\mathrm{b}}$ and Bingshe $\mathrm{Xu}{ }^{\mathrm{b}}$
}

A simple and low-cost spin-coating method was proposed to form a spontaneously distributed embossed structure. With such an embossed structure produced by $\mathrm{Al}_{2} \mathrm{O}_{3}$ nanospheres (NPs) with different diameters, the out-coupling efficiency is increased in all viewing directions without introducing significant spectral changes and the efficiency roll-off is suppressed at the same time. When the concentration of $\mathrm{Al}_{2} \mathrm{O}_{3}$ ethanol solution is chosen as $0.08 \mathrm{mg} \mathrm{ml}^{-1}$, a peak current efficiency (CE) of $52.1 \mathrm{~cd} \mathrm{~A}^{-1}$, peak power efficiency (PE) of $32.7 \mathrm{l} \mathrm{m} \mathrm{W}^{-1}$, and peak external quantum efficiency (EQE) of $20.9 \%$ are obtained. From the maximum efficiency value to the case where the brightness is $3000 \mathrm{~cd} \mathrm{~m}^{-2}$, the roll-off of $\mathrm{CE}, \mathrm{PE}$ and EQE for device B are only $6.53 \%, 26.30 \%$ and $6.22 \%$, respectively. The improved properties are attributed to greatly enhanced light extraction and an enlarged charge carrier recombination region.

\section{Introduction}

OLEDs hold great promise for both large area displays and lighting due to their excellent light-emitting performance. ${ }^{\mathbf{1 - 9}}$ Especially, phosphorescent OLEDs (PHOLEDs) have received considerable attention compared with fluorescent OLEDs, owing to their almost $100 \%$ internal quantum efficiency (IQE) by efficiently utilizing both singlet and triplet excitons. ${ }^{1}$ However, one of the major drawbacks of conventional OLEDs is poor light extraction efficiency. Although the IQE of PHOLEDs can be close to $100 \%$, their maximum EQE is only $20 \%,{ }^{10-12}$ as a large proportion of spontaneous emission is trapped as different kinds of optical modes within the device, ${ }^{13-17}$ e.g., the substrate mode due to total internal reflection (TIR) caused by the mismatch of refractive indices between air $(n=1)$ and glass substrate $(n=1.5)$, the waveguide mode for the TIR at the glass/ ITO layer $(n \approx 1.9)$ interface, or surface plasmon polariton (SPP) mode on the metal surface.

Therefore, many methods have been done around increasing the out-coupling efficiency of OLEDs, including: using microlens array, ${ }^{\mathbf{1 8 - 2 0}}$ large half sphere lens, ${ }^{21}$ surface roughness at the glass/air interface, ${ }^{22}$ periodic photonic crystal, ${ }^{23-25}$ microcavity OLEDs,${ }^{26-28}$ high index substrates, ${ }^{29}$ metal free OLED, ${ }^{30}$ and spontaneously formed buckles. ${ }^{31-34}$ Among all these techniques,

${ }^{a}$ Key Lab of Advanced Transducers and Intelligent Control System of Ministry of Education, College of Physics and Optoelectronics, Taiyuan University of Technology, Taiyuan 030024, China. E-mail: haoyuyinghyy@sina.com

${ }^{b}$ Key Laboratory of Interface Science and Engineering in Advanced Materials, Taiyuan University of Technology, Taiyuan 030024, China introducing spontaneously formed buckles in OLEDs have been proved to be an effective approach because of the enhanced light extraction without introducing spectral changes and directionality. This means the color gamut does not alter along the viewing direction, which is important for information displays.

However, the spontaneously formed buckles were usually fabricated by the techniques such as multiplexing light interference $^{32}$ or nano-imprinting, ${ }^{33,34}$ which require more complicated and expensive fabrication processes and thus are not costeffective for commercial applications. Thus, further studies are still required to increase out-coupling efficiency without spectral changes through a simple and cost-effective process.

In this letter, a randomly distributed scattering structure was developed by a simple low-cost solution based method. Herein the $\mathrm{Al}_{2} \mathrm{O}_{3}$ ethanol solution was spin-coated on the annealed PEDOT:PSS/ITO/glass film, then randomly placed $\mathrm{Al}_{2} \mathrm{O}_{3}$ NPs were obtained as a single layer. All the function layers deposited on $\mathrm{Al}_{2} \mathrm{O}_{3}$ NPs single layer were conformably patterned in such an OLED. Some substrate, waveguide and SPP modes which are confined in flat device can be extracted out into the air by such an embossed structure with color stability over all viewing angles. As a result, the prominent enhancement of $52.3 \%, 94.6 \%$, and $52.6 \%$ in peak CE, PE, and EQE is achieved and the efficiency rolloff is improved relative to the planar device. We have attributed this effect to the enlarged charge carrier recombination region and decreased triplet exciton density. This method is expected to be useful for low-cost, large scale manufacturing of PHOLEDs with high efficiency and low efficiency roll-off. 


\section{Experimental}

\subsection{Preparation of embossed PHOLED using $\mathrm{Al}_{2} \mathrm{O}_{3} \mathrm{NPS}$}

Fig. 1(a) shows the schematic diagram of the embossed PHOLED. The proposed embossed PHOLED has the structure of ITO/PEDOT:PSS/Al ${ }_{2} \mathrm{O}_{3}$ NPs/NPB (30 nm)/CBP:6 wt\% Ir(ppy) $)_{3}(30$ $\mathrm{nm}) /$ Bphen $(40 \mathrm{~nm}) / \mathrm{LiF}(1 \mathrm{~nm}) / \mathrm{Al}(150 \mathrm{~nm})$, where PEDOT:PSS [poly(3,4-ethylenedioxythiophene):polystyrenesulfonate] is used as the hole injection layer, NPB $\left[N, N^{\prime}\right.$-bis(naphthalen-1-yl)- $N, N^{\prime}$ bis(phenyl)benzidine] as hole-transport-layer (HTL), CBP [4, $4^{\prime}$ bis(carbazol-9-yl)-biphenyl] as the host of emitting layer (EML), $\operatorname{Ir}(\mathrm{ppy})_{3}$ [tris(2-phenylpyridine) iridium(III)] as phosphorescent dopant, Bphen [4,7-diphenyl-1,10-phenanthroline] as hole blocking layer (HBL) and electron transporting layer (ETL), respectively.

The PEDOT:PSS aqueous solution was commercially purchased from Heraeus with concentration of $1 \mathrm{~g} \mathrm{ml}{ }^{-1} \cdot \mathrm{Al}_{2} \mathrm{O}_{3}$ NPs powder was purchased from Shanghai ST-nano Science \& Technology Co., Ltd. The mean diameters of the received $\mathrm{Al}_{2} \mathrm{O}_{3}$ NPs are 300 and $500 \mathrm{~nm}$, respectively. These two kinds of $\mathrm{Al}_{2} \mathrm{O}_{3}$ NPs were firstly mixed according to the weight ratio of $1: 1$, and then diluted with ethanol. The resulting concentrations of $\mathrm{Al}_{2} \mathrm{O}_{3}$

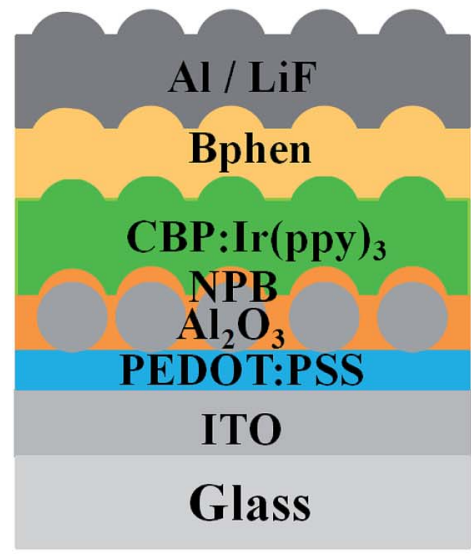

(a)

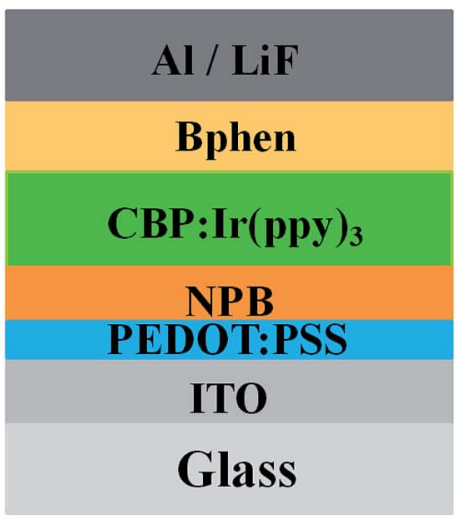

(b)

Fig. 1 The schematic diagrams of (a) the embossed PHOLED and (b) the planar PHOLED. in ethanol solution are $0.2,0.08$ and $0.04 \mathrm{mg} \mathrm{ml}^{-1}$ for devices A, $\mathrm{B}$ and $\mathrm{C}$, respectively, which is the only difference among the three devices. Other organic materials were purchased from Nichem Fine Technology Co., Ltd., and all materials were used as received.

The preparation process of embossed PHOLEDs is as follows. Glass substrates coated by indium tin oxide (ITO) with a sheet resistance of $10 \Omega \mathrm{sq}^{-1}$ were pre-cleaned in turn by ultrasonic treatment in deionized water and acetone, and then treated by UV ozone for $15 \mathrm{~min}$. Subsequently, aqueous solution of PEDOT:PSS was spin-coated onto ITO at the spin rate of $3000 \mathrm{rpm}$ for $60 \mathrm{~s}$, then annealed at $120^{\circ} \mathrm{C}$ for $15 \mathrm{~min}$ in the air ambient. Continuously, the $\mathrm{Al}_{2} \mathrm{O}_{3}$ ethanol solution after being stirred for $4 \mathrm{~h}$ at the temperature of $60{ }^{\circ} \mathrm{C}$ was spin-coated at the spin rate of $3000 \mathrm{rpm}$ for $60 \mathrm{~s}$ on the annealed PEDOT:PSS films, then randomly placed $\mathrm{Al}_{2} \mathrm{O}_{3}$ NPs were obtained as a single layer. The following layers, including $30 \mathrm{~nm}$-thick NPB, $30 \mathrm{~nm}$-thick CBP:Ir(ppy) ${ }_{3}, 40 \mathrm{~nm}$-thick Bphen, $1 \mathrm{~nm}$-thick LiF, and $150 \mathrm{~nm}$ thick $\mathrm{Al}$ were in turn deposited on randomly placed $\mathrm{Al}_{2} \mathrm{O}_{3} \mathrm{NPs}$ layer using thermal evaporation in high vacuum system with base pressure $<5 \times 10^{-4} \mathrm{~Pa}$ at deposition rates of $0.1 \mathrm{~nm} \mathrm{~s}^{-1}$ for organic materials, $0.01 \mathrm{~nm} \mathrm{~s}^{-1}$ for $\mathrm{LiF}$ and $0.5 \mathrm{~nm} \mathrm{~s}^{-1}$ for $\mathrm{Al}$, respectively. The doped layers were performed by co-evaporating host and dopant loaded in the separate heating sources. The thickness and the evaporating rate of individual layers were monitored by quartz crystal monitors, which have been cross-calibrated with ellipsometry measurements for ensuring high accuracy.

For comparison, a planar structure named device $\mathrm{D}$ was designed and prepared, of which $\mathrm{Al}_{2} \mathrm{O}_{3}$ NPs layer was free, which was the only difference between the planar and the embossed structure. The schematic diagram of the planar PHOLED is shown in Fig. 1(b).

\subsection{Characterization}

The scanning electron microscopy (SEM) images of the emitting layer were investigated by SEM/FIB Crossbeam Workstation LYRA $3 \mathrm{XMH}$. The luminance-current-voltage $(L-C-V)$ characteristics of the devices were measured by KEITHLEY 2400 and ST-900 M. The transmission spectra were measured by Shimadzu UV-2600 UV-vis spectrophotometer. The electroluminescent (EL) and photoluminescent (PL) spectra were recorded by SpectraScan PR 655 and Fluoromax-4 spectrophotometer, respectively. All the measurements were carried out at room temperature under ambient conditions.

\section{Results and discussion}

The SEM image of the surface of the embossed CBP:Ir(ppy $)_{3}$ EML based on $\mathrm{Al}_{2} \mathrm{O}_{3}$ NPs is shown in Fig. 2(a). For comparison, the SEM image of the planar CBP:Ir(ppy) ${ }_{3}$ EML is also given in Fig. 2(b). It can be seen clearly from Fig. 2(a) that on the surface of CBP:Ir(ppy) $)_{3} / \mathrm{NPB} / \mathrm{Al}_{2} \mathrm{O}_{3} \quad \mathrm{NPs} / \mathrm{PEDOT}: \mathrm{PSS} / \mathrm{ITO} /$ glass film, there are many randomly distributed globular bulges with different diameters induced by $\mathrm{Al}_{2} \mathrm{O}_{3}$ nanoparticles embedded in the bottom of NPB layer. In contrast, the surface morphology 


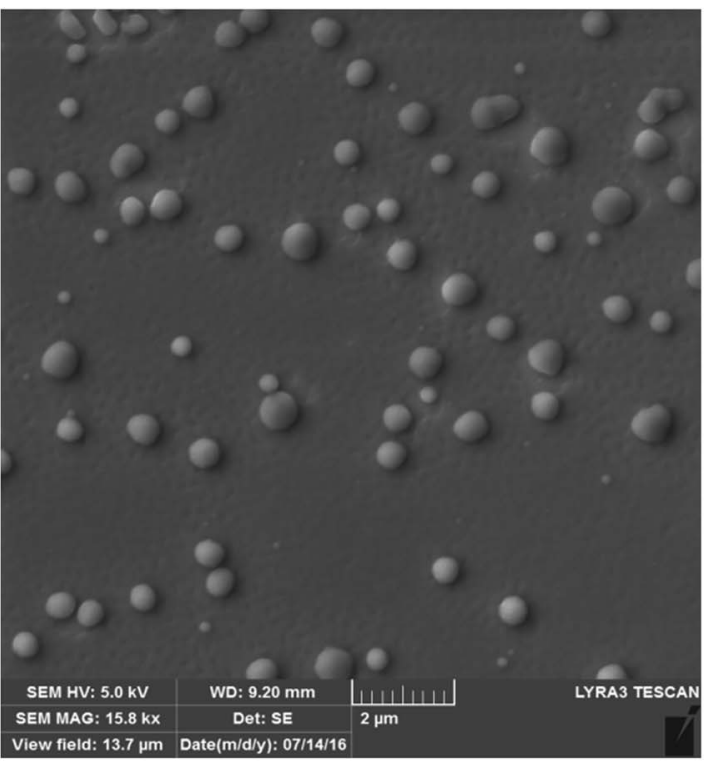

(a)

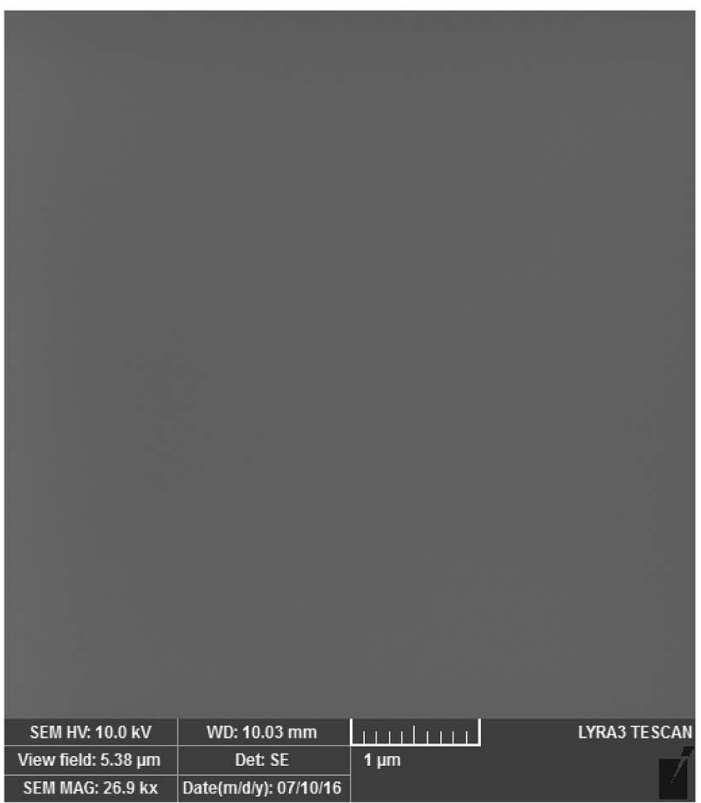

(b)

Fig. 2 SEM images of the surfaces of (a) the embossed CBP:Ir(ppy) 3 EML based on $\mathrm{Al}_{2} \mathrm{O}_{3} \mathrm{NPS}$, and (b) the planar CBP:Ir(ppy) ${ }_{3} \mathrm{EML}$.

of CBP:Ir(ppy) $)_{3} / \mathrm{NPB} / \mathrm{PEDOT}: \mathrm{PSS} / \mathrm{ITO} /$ glass film without $\mathrm{Al}_{2} \mathrm{O}_{3}$ NPs in Fig. 2(b) is extremely smooth.

Fig. 3(a) shows the current density versus voltage characteristics of all devices. It is observed that the driving voltages of devices A-D at current density of $100 \mathrm{~mA} \mathrm{~cm}^{-2}$ are 6.5, 7.8, 8.5 and $11.5 \mathrm{~V}$, respectively. This means all embossed devices have much lower driving voltages than planar one at the same current density. What's more, the driving voltages of the embossed devices decrease with the increase of the concentration of $\mathrm{Al}_{2} \mathrm{O}_{3} \mathrm{NPs}$ solution. The driving voltage of device $\mathrm{A}$ was the lowest among all the devices, as seen in Fig. 3(a), in spite of
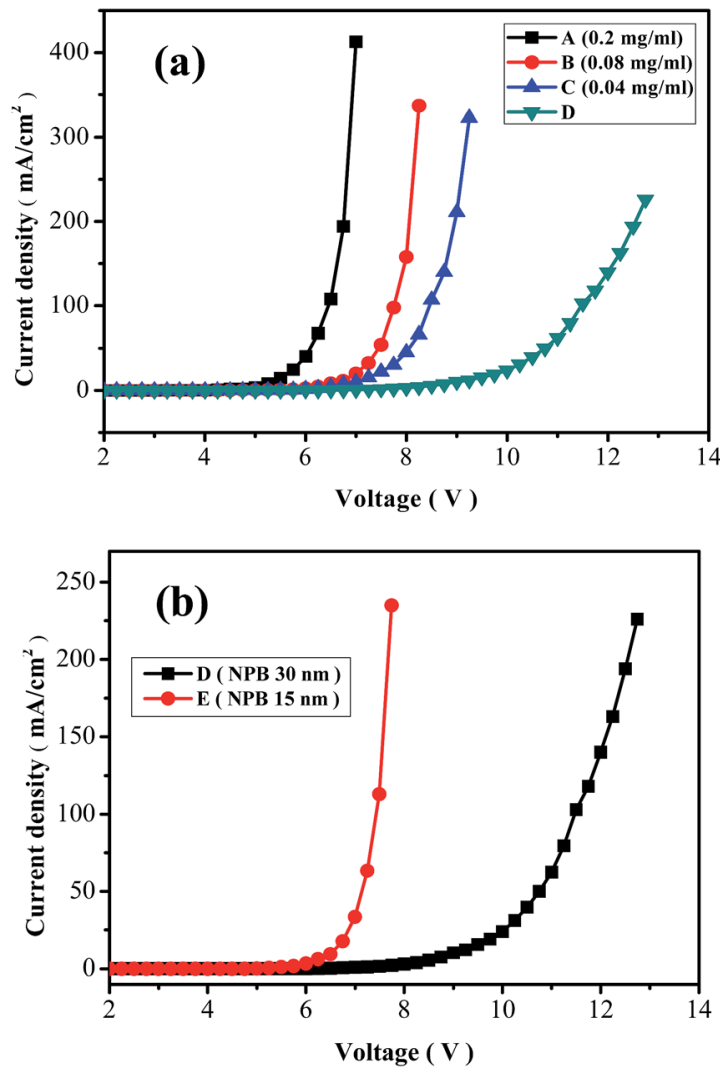

Fig. 3 Current density-voltage characteristics of (a) devices A-D, and (b) devices $\mathrm{D}$ and $\mathrm{E}$.

the largest amount of insulating $\mathrm{Al}_{2} \mathrm{O}_{3}$ NPs. The distinctly lower driving voltage of device A may result from the partially reduced organic layer thicknesses and the enhanced electric field just because the structural change by the introduce of $\mathrm{Al}_{2} \mathrm{O}_{3} \mathrm{NPs}^{34-37}$ To verify this conclusion, we fabricated another device named device $\mathrm{E}$ with the same structure with device $\mathrm{D}$ except thinner thickness of NPB layer $(15 \mathrm{~nm})$. The current density-voltage characteristics of devices D and $\mathrm{E}$ are shown in Fig. 3(b). It can be seen clearly that the driving voltage of device $\mathrm{E}$ is obviously lower than that of device D at the same current density, which

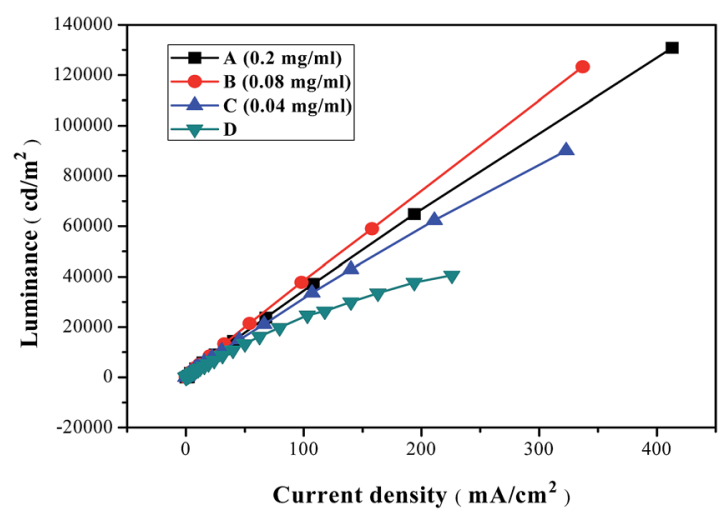

Fig. 4 Luminance-current density characteristics of devices A-D. 

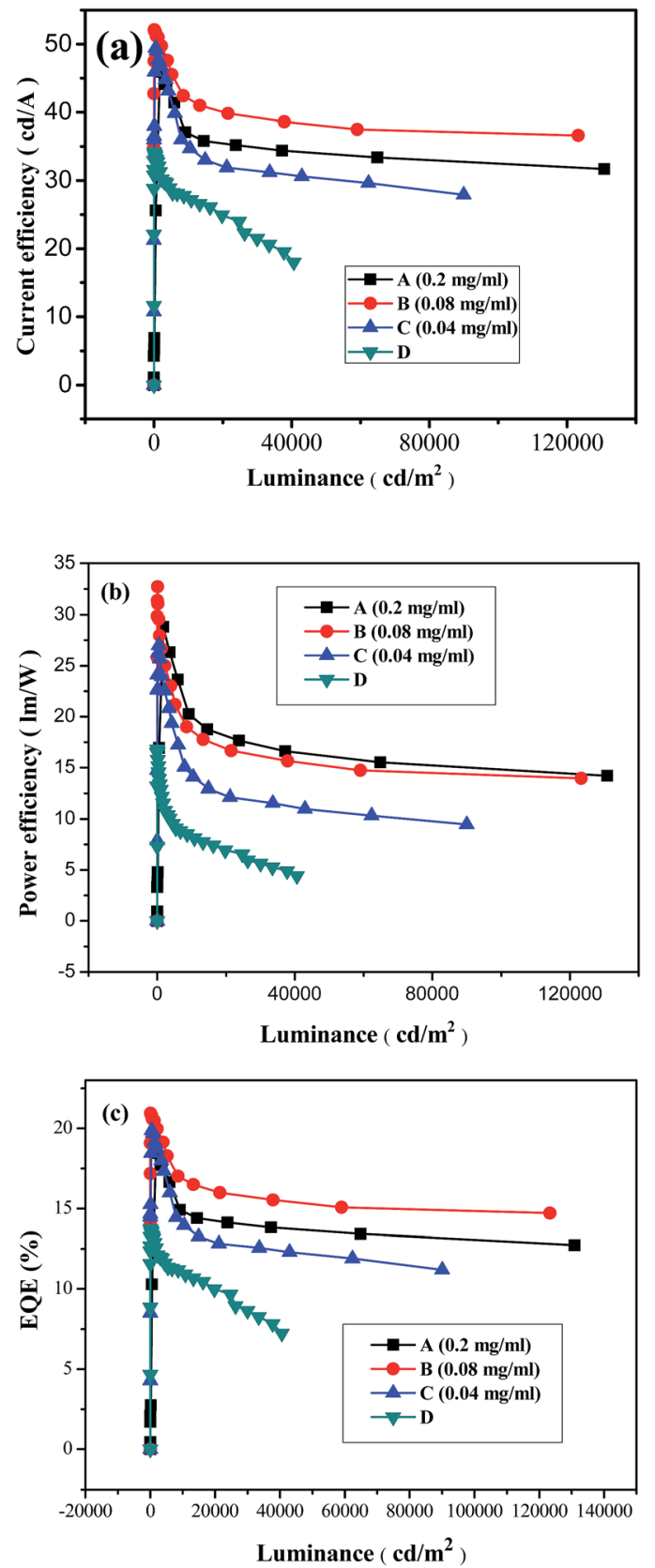

Fig. 5 Efficiency performances of the embossed and planar $\mathrm{PHO}$ LEDs: (a) CE-luminance, (b) PE-luminance, and (c) EQE-luminance characteristics of devices A-D.

proves that the reduced organic layer thickness can cause remarkably decrease in device driving voltage.

The luminance versus current density curves of all devices are shown in Fig. 4. At a constant current density of $100 \mathrm{~mA} \mathrm{~cm}{ }^{-2}$, the luminance of devices A-D is $34520,38571,31324$ and $24126 \mathrm{~cd} \mathrm{~m}^{-2}$, respectively. And the maximum brightness for devices A-D is $130868,123316,90035$ and $40600 \mathrm{~cd} \mathrm{~m}^{-2}$, respectively. That means the embossed PHOLEDs with $\mathrm{Al}_{2} \mathrm{O}_{3}$ film show more superior performance compared with the traditional planar device. Among them, the luminance of device B is the highest during all current density regions.
Table 1 The efficiency parameters of devices A, B, C and D

\begin{tabular}{|c|c|c|c|c|c|c|}
\hline \multirow[b]{2}{*}{ Device } & \multicolumn{2}{|c|}{$\mathrm{CE}\left(\mathrm{cd} \mathrm{A}^{-1}\right)$} & \multicolumn{2}{|c|}{$\mathrm{PE}\left(\operatorname{lm~W^{-1})}\right.$} & \multicolumn{2}{|c|}{ EQE (\%) } \\
\hline & Max. & $\begin{array}{l}\text { (a) } 3000 \\
\mathrm{~cd} \mathrm{~m}^{-2}\end{array}$ & Max. & $\begin{array}{l}\text { @3000 } \\
\mathrm{cd} \mathrm{m}^{-2}\end{array}$ & Max. & $\begin{array}{l}\text { @ } 3000 \\
\mathrm{~cd} \mathrm{~m}^{-2}\end{array}$ \\
\hline A & 46.0 & 44.6 & 28.8 & 27.1 & 18.4 & 17.9 \\
\hline B & 52.1 & 48.7 & 32.7 & 24.1 & 20.9 & 19.6 \\
\hline $\mathrm{C}$ & 49.4 & 45.6 & 27.0 & 21.6 & 19.9 & 18.3 \\
\hline D & 34.2 & 29.8 & 16.8 & 10.4 & 13.7 & 12.0 \\
\hline
\end{tabular}

Fig. 5 shows the CE, PE and EQE of devices A-D. The details of the efficiency performances of all devices are summarized in Table 1. It is observed that the devices containing $\mathrm{Al}_{2} \mathrm{O}_{3} \mathrm{NPs}$ have higher efficiencies compared with the planar device $\mathrm{D}$ under the same luminance. In particular, device $\mathrm{B}$ with the concentration of $\mathrm{Al}_{2} \mathrm{O}_{3} \mathrm{NPs}$ of $0.08 \mathrm{mg} \mathrm{ml}^{-1}$ has the highest CE, PE and EQE among all the four devices. Compared with device $\mathrm{D}$, device $\mathrm{B}$ exhibits a peak $\mathrm{CE}$ of $52.1 \mathrm{~cd} \mathrm{~A}^{-1}$ with the enhancement factor of $52.3 \%$, a peak PE of $32.7 \mathrm{~lm} \mathrm{~W}{ }^{-1}$ with the enhancement factor of $94.6 \%$, and a peak $\mathrm{EQE}$ of $20.9 \%$ with the enhancement factor of $52.6 \%$. What's more, the CE, PE and EQE values of the embossed devices keep at a significantly high level over all the observed luminance range. For example, the roll-off of $\mathrm{CE}, \mathrm{PE}$ and EQE from the maximum efficiency value to the case at the brightness of $3000 \mathrm{~cd} \mathrm{~m}^{-2}$ for device B are $6.53 \%, 26.30 \%$ and

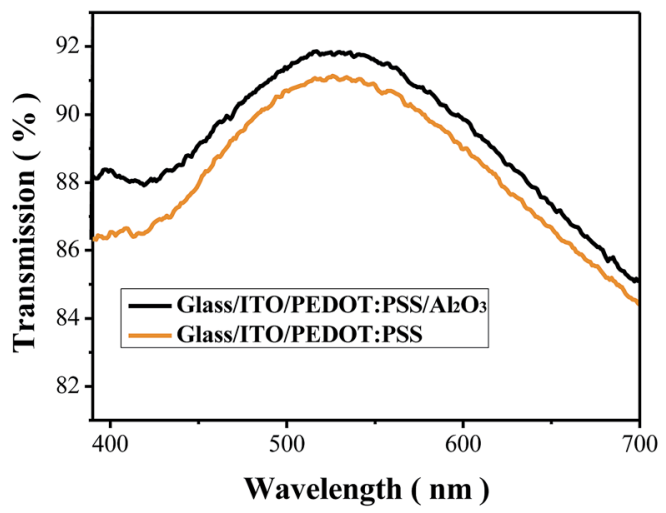

(a)

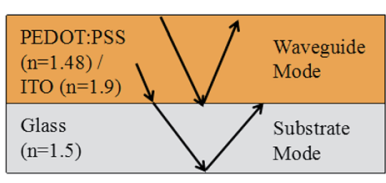

Air ( $\mathrm{n}=1)$

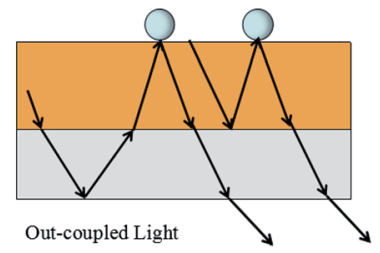

(b)
Fig. 6 (a) Transmission spectra of the concave-convex film with the structure of glass/ITO/PEDOT:PSS/ $/ \mathrm{Al}_{2} \mathrm{O}_{3} \mathrm{NPs}$ and the planar film with the structure of glass/ITO/PEDOT:PSS. (b) Schematic diagram of waveguide and substrate mode losses in planar film (left) and light extraction in concave-convex film (right), and the refractive index $n$ is also shown in the diagram. 

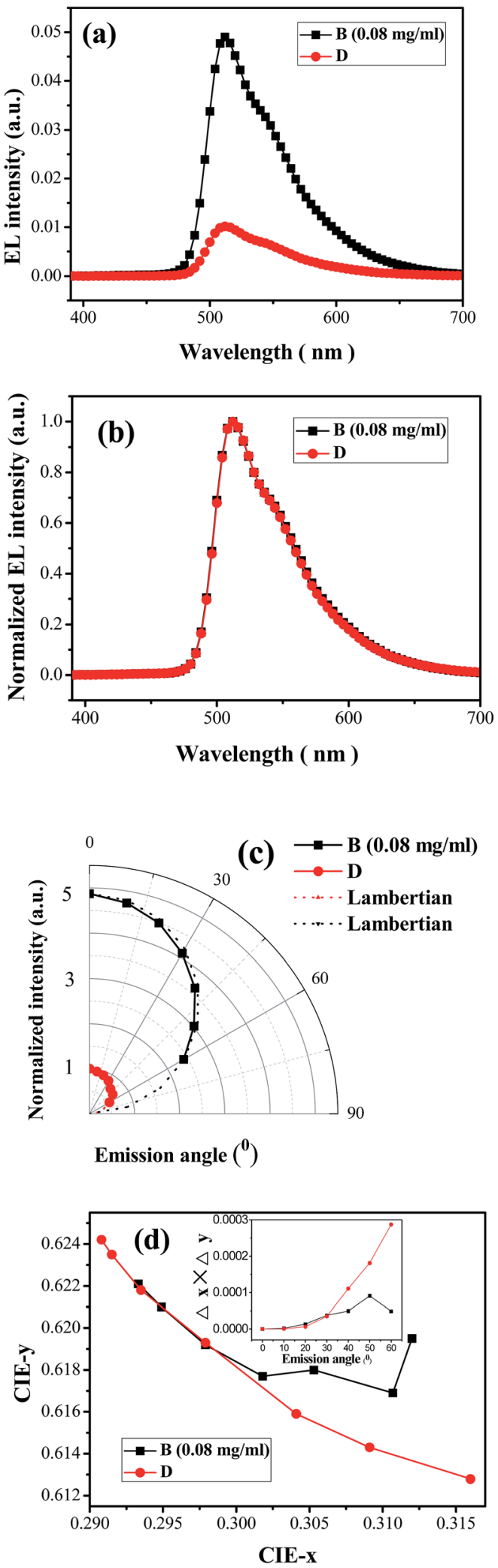

Fig. 7 Luminescence spectral characteristics: (a) EL spectra of embossed and planar PHOLEDs measured at the surface normal direction at a voltage of $7 \mathrm{~V}$. (b) Normalized EL spectra. (c) Viewing angle dependence of EL intensity for the embossed PHOLED (device B, black squares) and planar PHOLED (device D, red circles), normalized with the intensity of planar device in the surface normal direction, and the dashed lines represent the ideal Lambertian emission pattern. Both
$6.22 \%$, respectively, while for device D the corresponding rolloff are $12.87 \%, 38.10 \%$ and $12.41 \%$ respectively, which are $1.97,1.45$ and 1.99 times those of device B. In a word, compared with the planar device $\mathrm{D}$, the embossed devices show not only higher efficiencies but also lower efficiency roll-off. Although the PE of device B is slightly lower than that of device A as the luminance increases owing to slightly higher working voltages, the performance of device $\mathrm{B}$ is still considered as the most outstanding one among all devices, considering CE and EQE profile.

In addition, it is noted that NPB is not optimized as the hole transporting layer in our devices, due to its lower triplet energy $(2.29 \mathrm{eV})$ than that of the $\operatorname{Ir}(\mathrm{ppy})_{3}(2.42 \mathrm{eV})$, which easily lead to quenching of the excitons formed in $\operatorname{Ir}(\mathrm{ppy})_{3}$ by energy transfer to NPB. When a hole transporting material with higher triplet energy than that of $\operatorname{Ir}(\mathrm{ppy})_{3}$ is used, such as PHCZ2, ${ }^{38}$ the performance of our proposed device will be more excellent. For all that, the utilization of NPB still does not cover up the advantage of our proposed structure.

The remarkable performance improvement of the embossed devices is contributed by several factors. First, it is considered that the concave-convex structure formed by $\mathrm{Al}_{2} \mathrm{O}_{3}$ NPs actually shortens the organic layer thicknesses, enhances the electric field, which improves the hole and electron injection and transportation. Next, the concave-convex structure will broaden the charge carrier recombination region, which avoids exciton accumulation, decreases the triplet exciton density, and suppresses triplet exciton annihilation (TTA) and tripletpolaron annihilation (TPA), and then leads to the increase of efficiency and the reduction of efficiency roll-off in the embossed devices. Finally, the introduce of $\mathrm{Al}_{2} \mathrm{O}_{3}$ NPs and the conformably patterned function layers deposited on randomly placed $\mathrm{Al}_{2} \mathrm{O}_{3}$ NPs layer can intensify light out-coupling, and extrate more photons out of the embossed devices which are confined by substrate, waveguide and SPP modes in the planar one. Compared with device $\mathrm{B}$, the slightly lower efficiencies of device A originate from the high concentration of $\mathrm{Al}_{2} \mathrm{O}_{3}$ NPs which could cause more non-radiative traps and phosphorescence quenching centers, and thus poor device performances. As for device $\mathrm{C}$, the concentration of $\mathrm{Al}_{2} \mathrm{O}_{3} \mathrm{NPs}$ is too low to form enough concave-convex profiles, so the light extraction and roll-off suppression effects are not as good as device B.

To further confirm the enhancement effect of light extraction by $\mathrm{Al}_{2} \mathrm{O}_{3}$ NPs, a concave-convex film with the structure of glass/ ITO/PEDOT:PSS/ $/ \mathrm{Al}_{2} \mathrm{O}_{3}$ NPs and a planar film with the structure of glass/ITO/PEDOT:PSS were prepared, respectively. All PEDOT:PSS films were formed by the same method with the PHOLEDs mentioned before (spin-coated, $3000 \mathrm{rpm}$ for $60 \mathrm{~s}$, and annealed, $120{ }^{\circ} \mathrm{C}$ for $15 \mathrm{~min}$ ), and the concentration of $\mathrm{Al}_{2} \mathrm{O}_{3}$ NPs is $0.08 \mathrm{mg} \mathrm{ml}^{-1}$, the same with device $\mathrm{B}$. The UV-vis

embossed and planar PHOLEDs show a maximum EL intensity in the normal direction and the emission intensities of the two devices are almost identical to the Lambertian emission pattern. (d) The CIE color coordinates for the emission angles from $0^{\circ}$ to $60^{\circ}$ with $10^{\circ}$ step. Inset of (d): the product of the variation of CIE indices, $|\Delta x \times \Delta y|$, at different emission angles. 
transmission spectra of the two films are shown in Fig. 6(a). One can see clearly that the transmission of the concave-convex film is higher than that of the planar one at all wavelengths, which means when light is incident from the $\mathrm{Al}_{2} \mathrm{O}_{3}$ NPs layer, more light will be extracted into the air from the glass layer. This is attributed to the enhanced extraction of waveguide modes at the ITO/glass interface and substrate mode at the glass/air interface by the light scattering effect of $\mathrm{Al}_{2} \mathrm{O}_{3}$ NPs [Fig. 6(b)]. In addition, all functional layers such as EML and $\mathrm{Al}$ cathode layers in the embossed device are modulated into concaveconvex profiles, therefore, the photons trapped in waveguide mode by TIR at PEDOT:PSS/NPB interface for the great difference of refractive indices between PEDOT:PSS $(n=1.48)$ and NPB $(n=1.79)$ and the photons lost as SPP mode on the metal surface in planar device can be extracted out as well. As a result, randomly arranged patterns of the embossed devices can enhance the out-coupling of substrate, waveguide and SPP modes.

Next, we investigated the luminescence spectra of the embossed device B and the planar device D. Fig. 7(a) shows the EL spectra for the two PHOLEDs measured at the surface normal direction at a voltage of $7 \mathrm{~V}$. The enhancement of EL intensity in the device with $\mathrm{Al}_{2} \mathrm{O}_{3}$ NPs over the reference one is caused by two reasons. Firstly, the current density of the embossed device is higher than that of the planar one under the
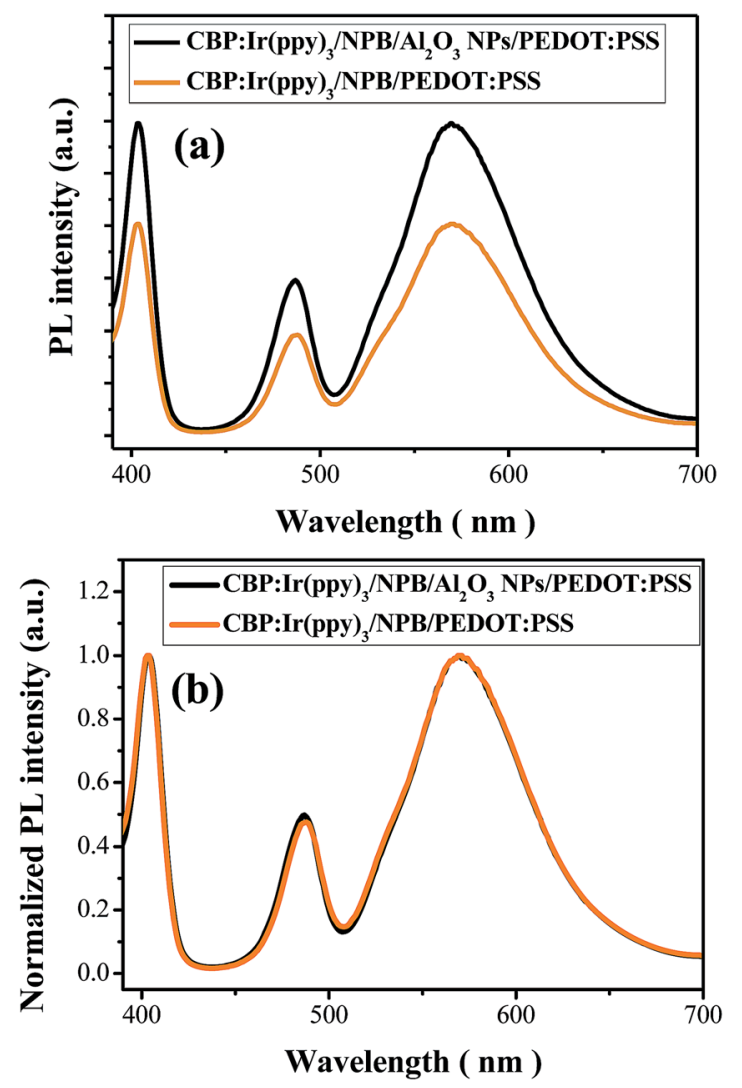

Fig. 8 (a) PL spectra and (b) normalized PL spectra of the patterned CBP:Ir(ppy $)_{3} / \mathrm{NPB} / \mathrm{Al}_{2} \mathrm{O}_{3} \mathrm{NPS} / \mathrm{PEDOT}: \mathrm{PSS}$ and the planar CBP:Ir(ppy) ${ }_{3} /$ NPB/PEDOT:PSS films same voltage, and the luminance will increase with the increase of current density. Secondly, the luminance of the embossed device is higher than that of the planar one under the same current density for the enhancement of light out-coupling and the reduction of triplet exciton quenching. Fig. 7(b) shows that the shape of the normalized EL emission spectrum of the embossed device is very similar to that of the planar one. The viewing angle dependence of EL intensity is shown in Fig. 7(c) and color coordinates are shown in Fig. 7(d). Fig. 7(c) presents the integration of EL spectra of device B and D over the entire wavelength region from 380 to $780 \mathrm{~nm}$ for the emission angles from $0^{\circ}$ to $60^{\circ}$ with $10^{\circ}$ step and the data were normalized with the integration value of the EL spectra of planar device $D$ in the surface normal direction. One can see that both embossed and planar PHOLEDs show a maximum EL intensity in the normal direction, the emission intensities of the embossed device $\mathrm{B}$ are greater than those of the planar one at all angles, and both the emission intensities of the two devices are almost identical to the Lambertian emission pattern, which mean that the luminous intensity of the embossed device is enhanced without angular dependence. Additionally, Fig. 7(d) shows the CIE color coordinates do not change significantly for all viewing angles. The CIE indices of the embossed device in the normal direction are $(0.2933,0.6221)$, which are similar to those of the planar one $(0.2908,0.6242)$. The CIE indices of the embossed device vary within $\Delta x=6.0 \%$ and $\Delta y=0.8 \%$ from $0^{\circ}$ to $60^{\circ}$ and those of the planar one show similar variations of $\Delta x=8.0 \%$ and $\Delta y=1.9 \%$. And the product of the variation of CIE indices, $|\Delta x \times \Delta y|$, is under 0.0001 for the embossed device, and 0.0003 for the planer one [see the inset of Fig. 7(d)], which confirms that the embossed structure improve the light out-coupling without significant spectral changes. This quite uniform enhancement of light extraction over all the emission wavelengths from $380-780 \mathrm{~nm}$ is attributed to broadly and randomly distributed $\mathrm{Al}_{2} \mathrm{O}_{3}$ NPs. Similarly, the improved extraction of optical modes is also reflected in PL emission of concave-convex film, shown in Fig. 8(a). One can see from Fig. 8(a) the PL spectrum of the embossed film is obviously stronger than that of the planar one. The normalized PL emission spectra of the two films are almost identical. This result, similar to that of EL spectra, further shows that the embossed structure can enhance light extraction over all visible spectra.

\section{Conclusions}

In summary, we have introduced an extremely simple and effective spin-coating method to form spontaneously distributed buckling structures. The results indicate that the randomly embedded $\mathrm{Al}_{2} \mathrm{O}_{3}$ NPs used in PHOLEDs can decrease device driving voltages, enlarge charge carrier recombination region, decrease the triplet exciton density, and suppresses triplet exciton quenching. What's more, it can also enhance the outcoupling of substrate, waveguide and SPP modes in all viewing direction without introducing significant spectral changes. As a result, the embossed devices exhibit the best current efficiency of $52.1 \mathrm{~cd} \mathrm{~A}^{-1}$, power efficiency of $32.7 \mathrm{~lm} \mathrm{~W}^{-1}$, and EQE of $20.9 \%$, which are 1.52, 1.95 and 
1.53 times those of the reference device. Besides, the embossed devices also exhibit suppressed efficiency roll-off. The roll-off of $\mathrm{CE}, \mathrm{PE}$ and EQE from the maximum efficiency value to the case at the brightness of $3000 \mathrm{~cd} \mathrm{~m}^{-2}$ are $6.53 \%, 26.30 \%$ and $6.22 \%$, respectively, which are just $50.72 \%, 69.04 \%$ and $50.13 \%$ of those of the reference device. We conclude that such a low-cost and easy of large-scale fabrication method to form spontaneously distributed embossed structure fabricated simply by spincoating can be used to increase the out-coupling efficiency and decrease efficiency roll-off, which could have important applications in high-performance displays and broad spectrum lighting.

\section{Conflicts of interest}

There are no conflicts to declare.

\section{Acknowledgements}

This research work was financially supported by National Natural Science Foundation of China (61274056, 61475109 and 61275037), Key Research and Development (International Cooperation) Program of Shanxi (201603D421042), and Platform and Base Special Project of Shanxi (201605D131038). Y. Cui acknowledges the Young Talents Program and Young Sanjin Scholars Program of Shanxi Province.

\section{References}

1 C. Adachi, M. A. Baldo, M. E. Thompson and S. R. Forrest, J. Appl. Phys., 2001, 90, 5048.

2 M. A. Baldo, D. O'brien, Y. You, A. Shoustikov, S. Sibley, M. Thompson and S. Forrest, Nature, 1998, 395, 151.

3 B. W. D'Andrade and S. R. Forrest, Adv. Mater., 2004, 16, 1585.

4 Y. Li, Y. Hao, W. Li, S. Yuan, H. Liu, Y. Cui, H. Wang, B. Xu and W. Huang, Opt. Express, 2013, 21, 17020.

5 S. Yuan, Y. Hao, Y. Miao, Q. Sun, Z. Li, Y. Cui, H. Wang, F. Shi and B. Xu, RSC Adv., 2015, 5, 89041.

6 Q. Yang, Y. Hao, Z. Wang, Y. Li, H. Wang and B. Xu, Synth. Met., 2012, 162, 398.

7 Y. H. Yunfei Li, Z. Yan, H. Liu, H. Wang and B. Xu, Synth. Met., 2013, 164, 12.

8 Y. Miao, X. Du, H. Wang, H. Liu, H. Jia, B. Xu, Y. Hao, X. Liu, W. Li and W. Huang, RSC Adv., 2015, 5, 4261.

9 Y. Miao, Z. Gao, Y. Li, A. Zhang, H. Wang, Y. Hao, H. Jia, X. Liu and B. Xu, Synth. Met., 2015, 203, 59.

10 S. Reineke, F. Lindner, G. Schwartz, N. Seidler, K. Walzer, B. Lussem and K. Leo, Nature, 2009, 459, 234.

11 L. H. Smith, J. A. E. Wasey and W. L. Barnes, Appl. Phys. Lett., 2004, 84, 2986.

12 H. Uoyama, K. Goushi, K. Shizu, H. Nomura and C. Adachi, Nature, 2012, 492, 234.

13 W. Brütting, J. Frischeisen, T. D. Schmidt, B. J. Scholz and C. Mayr, Phys. Status Solidi A, 2013, 210, 44.
14 K. Hong and J.-L. Lee, Electron. Mater. Lett., 2011, 7, 77.

15 S. Nowy, B. C. Krummacher, J. Frischeisen, N. A. Reinke and W. Brütting, J. Appl. Phys., 2008, 104, 123109.

16 K. Saxena, V. K. Jain and D. S. Mehta, Opt. Mater., 2009, 32, 221.

17 L. H. Smith, J. A. E. Wasey, I. D. W. Samuel and W. L. Barnes, Adv. Funct. Mater., 2005, 15, 1839.

18 S.-H. Eom, E. Wrzesniewski and J. Xue, Org. Electron., 2011, $12,472$.

19 J. Lim, S. S. Oh, D. Y. Kim, S. H. Cho, I. T. Kim, S. H. Han, H. Takezoe, E. H. Choi, G. S. Cho, Y. H. Seo, S. O. Kang and B. Park, Opt. Express, 2006, 14, 6564.

20 S. Möller and S. R. Forrest, J. Appl. Phys., 2002, 91, 3324.

21 C. F. Madigan, M. H. Lu and J. C. Sturm, Appl. Phys. Lett., 2000, 76, 1650.

22 I. Schnitzer, E. Yablonovitch, C. Caneau, T. J. Gmitter and A. Scherer, Appl. Phys. Lett., 1993, 63, 2174.

23 Y. R. Do, Y. C. Kim, Y. W. Song, C. O. Cho, H. Jeon, Y. J. Lee and Y. H. Lee, Adv. Mater., 2003, 15, 1214.

24 Y.-C. Kim, S.-H. Cho, Y.-W. Song, Y.-J. Lee, Y.-H. Lee and Y. R. Do, Appl. Phys. Lett., 2006, 89, 173502.

25 M. Rattier, T. F. Krauss, J. F. Carlin, R. Stanley, U. Oesterle, R. Houdré, C. Smith, R. Delarue, H. Benisty and C. Weisbuch, Opt. Quantum Electron., 2002, 34, 79.

26 T. Fleetham, J. Ecton, G. Li and J. Li, Org. Electron., 2016, 37, 141.

27 J. Lee, N. Chopra, D. Bera, S. Maslov, S.-H. Eom, Y. Zheng, P. Holloway, J. Xue and F. So, Adv. Energy Mater., 2011, 1, 174.

28 C. Xiang, W. Koo, F. So, H. Sasabe and J. Kido, Light: Sci. Appl., 2013, 2, e74.

29 S. Mladenovski, K. Neyts, D. Pavicic, A. Werner and C. Rothe, Opt. Express, 2009, 17, 7562.

30 J. B. Kim, J. H. Lee, C. K. Moon, S. Y. Kim and J. J. Kim, Adv. Mater., 2013, 25, 3571.

31 D.-H. Kim, J. Y. Kim, D.-Y. Kim, J. H. Han and K. C. Choi, Org. Electron., 2014, 15, 3183.

32 T. B. Lim, K. H. Cho, Y. H. Kim and Y. C. Jeong, Opt. Express, 2016, 24, 17950.

33 W. H. Koo, S. M. Jeong, F. Araoka, K. Ishikawa, S. Nishimura, T. Toyooka and H. Takezoe, Nat. Photonics, 2010, 4, 222.

34 W. H. Koo, S. M. Jeong, S. Nishimura, F. Araoka, K. Ishikawa, T. Toyooka and H. Takezoe, Adv. Mater., 2011, 23, 1003.

35 A. O. Altun, S. Jeon, J. Shim, J.-H. Jeong, D.-G. Choi, K.-D. Kim, J.-H. Choi, S.-W. Lee, E.-S. Lee, H.-D. Park, J. R. Youn, J.-J. Kim, Y.-H. Lee and J.-W. Kang, Org. Electron., 2010, 11, 711.

36 M. Fujita, T. Ueno, K. Ishihara, T. Asano, S. Noda, H. Ohata, T. Tsuji, H. Nakada and N. Shimoji, Appl. Phys. Lett., 2004, 85, 5769.

37 W. H. Koo, W. Youn, P. Zhu, X.-H. Li, N. Tansu and F. So, Adv. Funct. Mater., 2012, 22, 3454.

38 S.-O. Jeon, K. S. Yook, C. W. Joo, J. Y. Lee, K.-Y. Ko, J.-Y. Park and Y. G. Baek, Appl. Phys. Lett., 2008, 93, 063306. 